\section{Regenerative approach in the treatment of grade II furcations: a case report}

\author{
Hasanuddin Thahir, Dian Setiawati*
}

CrossMark
Department of Periodontic, Faculty of Dentistry, Hasanuddin University, Makassar Indonesia

*Corresponding to: Dian Setiawati, Department of Periodontic, Faculty of Dentistry, Hasanuddin University, Makassar Indonesia setiawatidian44@gmail.com

Received: 10 June 2018

Revised: 15 June 2018

Accepted: 9 July 2018

Available Online 1 April 2019

\begin{abstract}
Objective: A grade II furcation involvement has been defined as a defect having a horizontal loss attachment of $3 \mathrm{~mm}$ or greater but not through the entire furcation. There are several techniques used alone or in combination considered to achieve periodontal regeneration. This case report aims to describe regenerative approach in the treatment of grade II furcation defects in maxillary molars.
\end{abstract}

Methods: A 43 years old male reported to the Department of Periodontics with a complaint of pain. At the initial visit, scaling and

root planning was done. It was followed by periodontal regenerative therapy using bone graft and resorbable membranes.

Results: The treatment for overall seemed success with healthy periodontium and complete closed defect with bone fill, based on the clinical and radiographic development of the patient at the end of six month follow up.

Conclusion: The regenerative approach such as resorbable GTR membrane with bone material was more effective than open debridement alone, in the treatment of furcation defects.

Keywords: Bone graft, Furcation defect, Guided tissue regeneration, Periodontitis, Periodontal treatment

Cite this Article: Thahir H, Setiawati D. 2019. Regenerative approach in the treatment of grade II furcations: a case report. Journal of Dentomaxillofacial Science. 4(1): 53-56. D0l: 10.15562/jdmfs.v4i1.750

\section{Introduction}

Furcation involvement may be defined as the invasion of the bifurcation and trifurcation of multirooted teeth by progression of chronic inflammation during periodontitis. ${ }^{1,2}$ A study found that furcation involvement is frequently more common in maxillary first and second molars than mandibular molars. This can be explained by the difficulty in accessing the proximal surfaces on maxillary molars for cleaning. ${ }^{3}$ The most common etiologic of furcation involvement is bacterial plaque but there are various predisposing and contributing factors that can aggravate the disease. ${ }^{4}$

The degree of furcation involvement is commonly used as a clinical indicator to qualify the severity of existing periodontal breakdown. The extent of furcation disease can be determined by evaluating parameters vertical bone loss, horizontal bone loss or both. Most classifications used to describe the severity of furcation involvement are related to the amount of horizontal attachment loss. ${ }^{5,6}$ Glickman has suggested the classification into grade I, grade II, grade III and grade IV. ${ }^{7}$ Grade II furcation lesion is a culdesac with a definite horizontal component. The horizontal loss of periodontal tissue support $>3$ mm but not through-and-through defect. ${ }^{8,9}$

The treatment and management of teeth with furcation involvement presents one of the greatest challenges in periodontal therapy. ${ }^{10,11}$ The therapy of furcation involvement depends primarily on the extent of the disease, the strategic importance of the affected tooth and on the degree of patient cooperation and compliance. Therapies must begin with the initial periodontal treatment (systemic and cause-related phases) followed by debridement to regenerative procedures and extraction if the lesion progresses. However, the treatment must be sustained by the adequate hygiene of the patient, and by the close monitoring of the clinician ${ }^{12}$ Elimination of the pocket by resective or regenerative procedures and making the area accessible for plaque control is the primary objective of any furcation therapy. ${ }^{13}$ There are several techniques used alone or in combination, which are considered to achieve periodontal regeneration, including bone grafts or substitutes, guided tissue regeneration, root surface modification and biological mediators. ${ }^{14}$

More recently, techniques aimed at using bone grafts and/or barrier materials have been evaluated in regenerating furcation defects grade II. ${ }^{9}$ An important objective of regenerative therapy has been a predictable clinical course of furcation defects after periodontal regeneration, as evidenced by the formation of a new attachment apparatus including bone, cementum and periodontal ligament. ${ }^{15}$ Periodontal surgery using guided tissue regeneration (GTR) using non resorbable membran and bioabsorbable barriers has been widely used to regenerate bone and establishing a new connective tissue attachment. ${ }^{16}$ One of the most important indications for GTR treatment is the class II furcation defect. Bone graft are widely use to promote 
bone formation and periodontal regeneration. Bone graft provide a structural framework for clot development, maturation and remodeling that supports bone formation in osseous defect. ${ }^{17}$

This case report aims to describe regenerative approach in the treatment of grade II furcation with bioabsorbable barriers and bonegraft for regeneration of furcation defects in maxillary molars region.

\section{Case Report}

A 43 years old male reported to Dental Hospital Department of Periodontic, Hasanuddin University Makassar, Indonesia with the chief complaint of pain and continuous discomfort in left upper back teeth region since 1 month. Upon clinical examination, the site revealed signs of inflammation, increased vertical probing depth and grade II buccal furcation

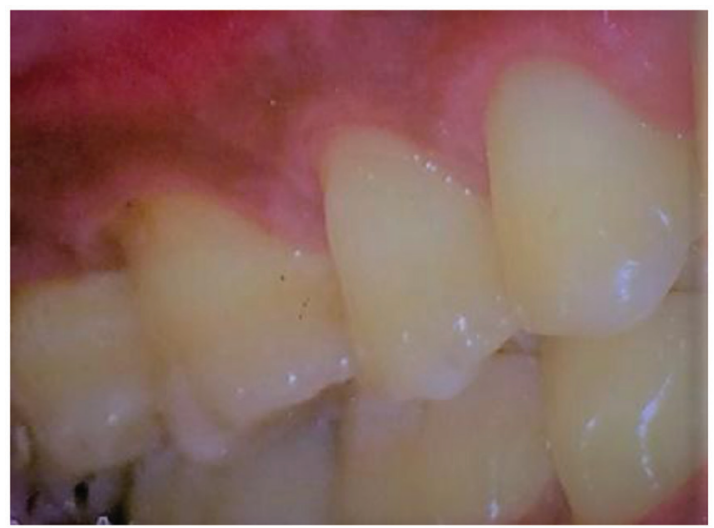

Figure 1 Preoperative view of tooth 26

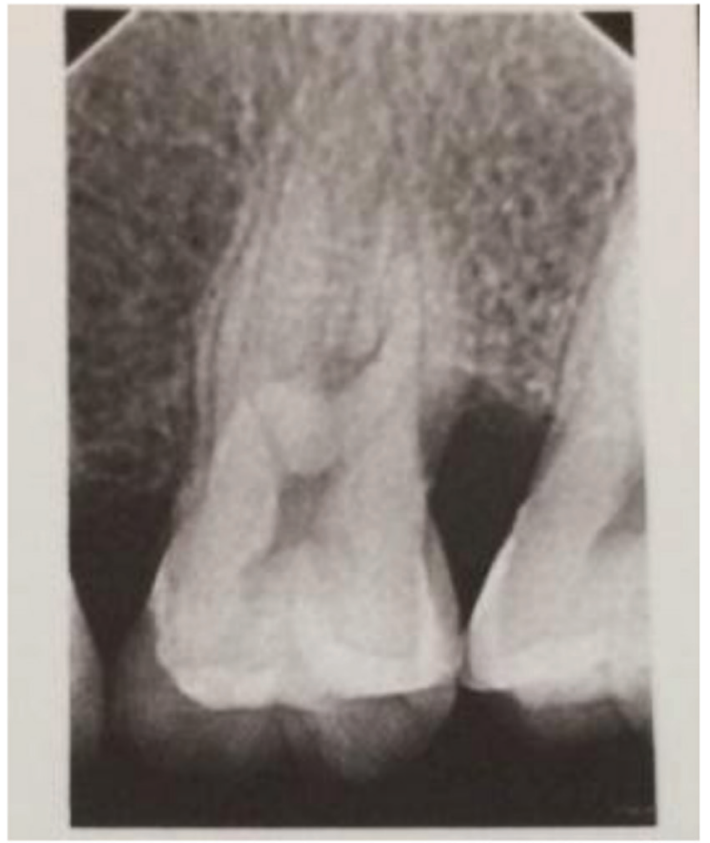

Figure 2 Preoperative intra oral periapical radiograph

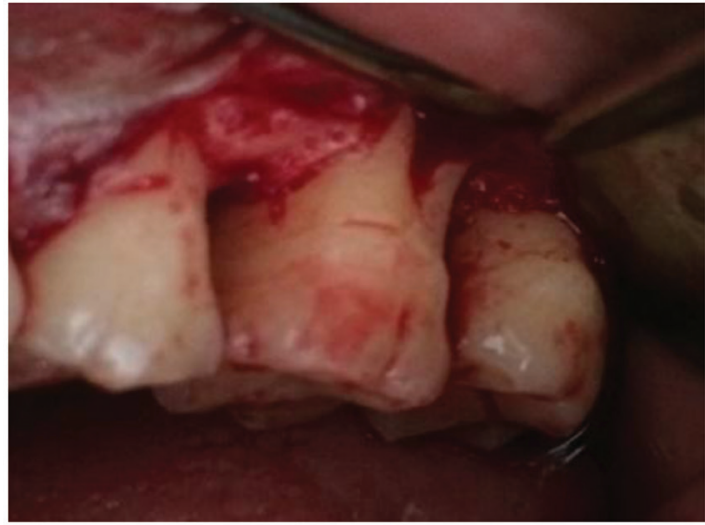

Figure 3 Furcation defect

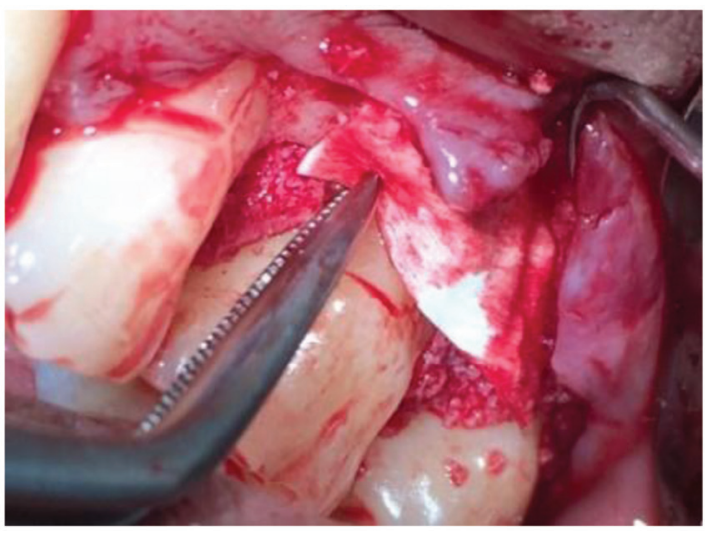

Figure 4 Bonegraft and membrane placed

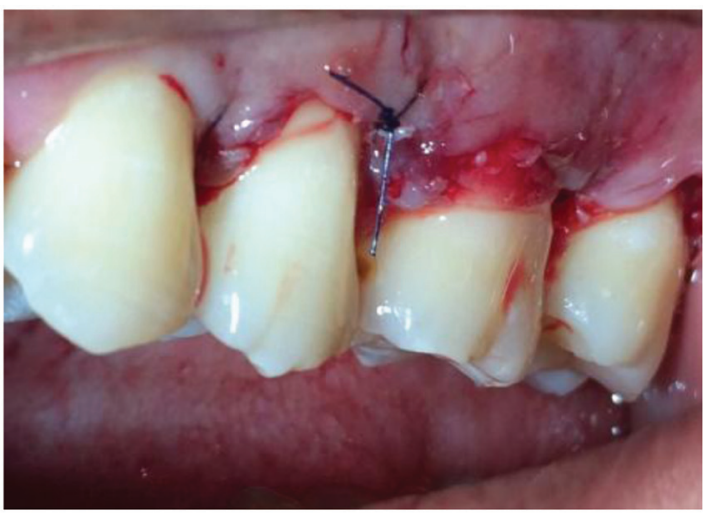

Figure 5 Suture placed

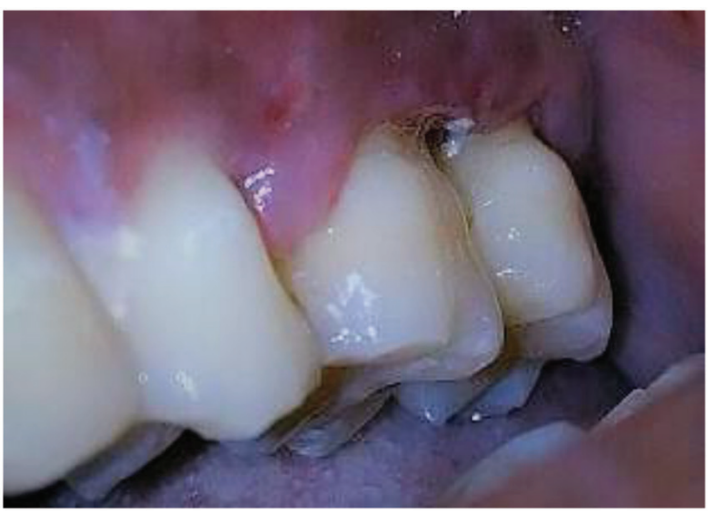

Figure 6 One week post operative 


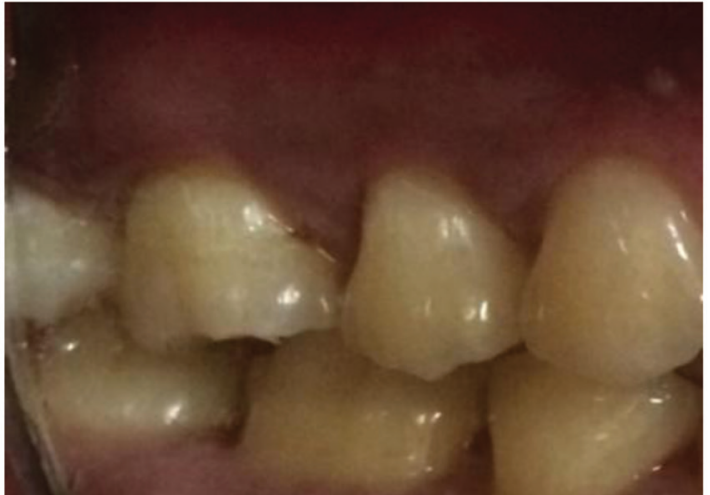

Figure 7 Clinical appearance 6 months post operative

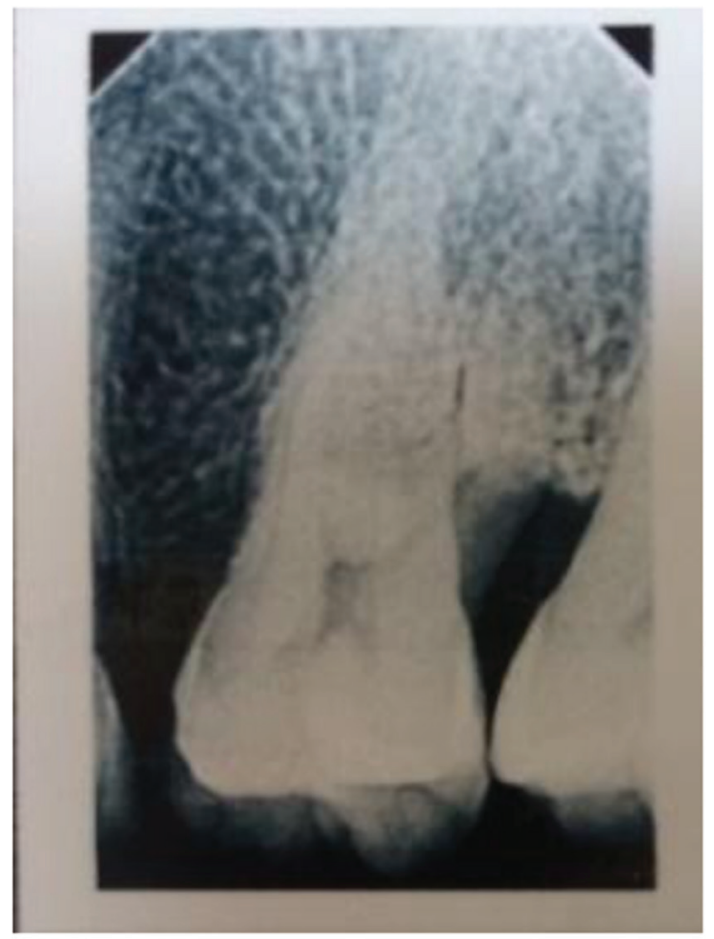

Figure 8 Radiographic features

involvement in \#26 figure 1. Periapical radiography was taken to confirm the presence and severity of furcation defect radiographically figure 2 .

The patient underwent initial therapy which included scaling and root planing, followed by oral hygiene instructions. The measurement probing pocket depth $(\mathrm{PD})=4 \mathrm{~mm}$, loss attachment level $(\mathrm{LA})=10 \mathrm{~mm}$, Horizontal furcation defect $(\mathrm{HFD})=4 \mathrm{~mm}$ was recorded. Clinical parameters were recorded at baseline and 6 months interval.

One week after the phase I therapy, patient was recalled for surgery. Prior to the surgery a signed informed consent was obtained from the patient. Surgical procedure was performed under proper aseptic precautions to keep the surgical site clean. After injecting local anesthesia, sulcular incisions were placed and a full thickness flap was elevated at the furcation site, extending at least one tooth mesial and distal to the affected tooth, and extended beyond mucogingival junction figure 3 . The defect area was thoroughly debrided and cleaned using Gracey curettes followed by ultrasonic scalers. After this, the defect area was condensed with the bone graft and covered by bioabsorbable GTR membrane figure 4 . Flaps were then repositioned and sutured figure 5. Periodontal dressing was applied over the site.

Antibiotics and analgesics were prescribed for one week and postoperative instructions were given. Patient was recalled for periodontal dressing and suture removal after 1 week figure 6 .

Six months post-operative periodontal examination revealed reduction in vertical probing depth figure 7 and radiographs revealed increased bone density figure 8 . This result indicating successful resolution of inflammation and periodontal regeneration in the furcation defect area.

\section{Discussion}

The ultimate goals of periodontal therapy are to regeneration of the lost attachment apparatus and a return to pre disease architecture. ${ }^{18}$ Multiple approaches have been used to resolve furcation defect including autografts, demineralized freezedried bone allografts (DFDBAs), bovine-derived xenografts, barrier membranes, and combinations of membranes and bone grafts. ${ }^{9}$

In the present case, combined treatment approach using bone graft and GTR membrane was used for treatment of mandibular grade II furcation defect. The bone graft material that used contains apatite carbonate (which is a component of bone) as well as a naturalized collagenized polymer.

A systematic review assessed the efficacy of membrane therapy in the treatment of periodontal furcation defects measured againts standard surgical periodontal treatment (i.e. open flap debridement) and confirmed superiority of guided tissue regeneration open flap debridement in class II furcation defects. ${ }^{2}$ The principle of GTR was promulgated for treatment of osseous defects in human periodontitis. The concept of GTR is based on the exclusion og gingival connective tissue cells and prevention of epithelial down growth into wound, thereby allowing cells with periodontal regenerative potential (PDL cells and bone cells) to enter the periodontal wound first. Barrier techniques, using material such as expanded polytetrafluoroethylene, polyglactin, polylactic acid, calcium sulfate and collagen are widely employed now a days, in the hope of excluding epithelium and the gingival corium (the conjunctive submucous layer) from reaching the root, the belief that they interfere with periodontal. $^{12}$ 
A few randomized clinical trials have investigated the clinical effectiveness of GTR in the treatment of class II maxillary furcation. Evidence indicates that GTR provides only limited advantages in the treatment of class II maxillary furcation. ${ }^{19}$ Class II furcation defects have the strongest level of evidence for predictable outcomes after regenerative therapy, that being combination therapy with barrier and bone replacement graft. ${ }^{20}$ Regeneration by grafting may be further enhanced by the use of barrier membranes that exclude gingival fibroblasts and epithelium from the healing site. It has also been shown that the guided tissue regeneration procedure, using membranes, holds promise for increasing the success of bone grafting. ${ }^{10}$

Bone graft healing can be divided into five stages continuum: inflammation (chemotaxis activity stimulated by necrotic debris), osteoblast differentiation from precursors, osteoinduction (osteoblast and osteoclast function activity), osteoconduction (new bone forming over scaffold) and remodeling which process continues for years. ${ }^{21}$

In the present case, the clinical parameters like horizontal furcation depth, vertical probing depth and clinical attachment level showed improvement when compared at 6 months from baseline. Comparisons between the initial and six-month postoperative radiograph revealed increased bone fill as revealed by the increased radio-opacity around the furcation area at six-month postoperative evaluation.

\section{Conclusion}

The result of the present case report suggest that the successful management of the furcation of maxillary molar by periodontal regenerative therapy for the grade II furcation involvement of 26 with bonegraft along with GTR membrane resulted in a significant amount of bone fill with improved clinical attachment levels and healthy gingiva.

\section{Acknowledgment}

The authors would like to thank to our supervisor, Prof. Dr. drg. Sri Oktawati, Sp.Perio for the valuable guidance and advice. We also would like to thank to chairman of Department of Periodontics Faculty of Dentistry Hasanuddin University, Dr. drg. A. Mardiana Adam, MS for providing us an opportunity to do this case. Also, we would like to take this opportunity to thank to the Director of Dental Hospital Hasanuddin University, drg. M. Ruslin, M.Kes., $\operatorname{Sp} . \mathrm{BM}(\mathrm{K})$ for providing us with a good environment and facilities to complete this project.

\section{Conflict of Interest}

The authors report no conflict of interest.

\section{References}

1. Nandkeoliar T, Ajay KEG, Dangi M, et al. Furcation-An unsolved mystery. Int J Clin Res 2014;2: 32-35.

2. Sanz M, Jepsen K, Eickholz P, et al. Clinical concepts for regenerative therapy in furcations. Periodontol 2000 2015;68: 308-332.

3. Najim U, Slotte C, Norderyd O. Prevalence of furcation-involved molars in a swedish adult population. A Radiographic Epidemiological Study. Clin Exp Dent Res 2016;2: 104-111.

4. Parihar AS, Katoch V. Furcation Involvement and Its Treatment: A Review. J Adv Med \& Dent Sci Res 2015;3: 81-87.

5. Walter C, Weiger R, Zitzmann Nu. Periodontal surgery in furcation-involved maxillary molars revisited an introduction of guidelines for comprehensive treatment. Clin Oral Invest 2011;15: 9-20.

6. Sánchez-Pérez A, Moya-Villaescusa MJ. Periodontal disease affecting tooth furcations. A Rev Treatm Avai 2009;14: 10-13.

7. Newman MG, Takei HH, Klokkevold PR, et al. Carranza’s clinical periodontology. 11th ed. 2012. p. 34-44.

8. Zaveri H, Rathva V, Sant A, et al. Triphala: an alternative therapy in periodontics-a critical review. J Clin Periodontol Implant Dent 2016;1: 5-11.

9. Avila-Ortiz G, Buitrago Jg De, Reddy Ms. Periodontal regeneration-furcation defects: a systematic review from the AAP regeneration workshop. J Periodontol 2015;5.

10. Khanna D, Malhotra S, Naidu DV. Treatment of grade II furcation involvement using resorbable guided tissue regeneration membrane: a six-month study. J Indian Soc Periodontol 2012;16: 404-410.

11. Mapara M, Jagtap R, Kanagotagi S, et al. Treatment of bilateral furcation involvements with bonegraft and bioabsorbable barriers. J Contemp Dentist 2012;2: 20-24.

12. Marinescu A, Carligeriu V, Nica L, et al. Evaluation of treatment techniques for advanced ( grade ii - iv) furcation defects : a literature review of the regenerative methods. TMJ 2011;61: 115-124.

13. Bhatnagar MA, Deepa D. Management of grade II furcation defect in mandibular molar with alloplastic bone graft and bioresorbable guided tissue regeneration membrane : a case report. Int J Periodontol \& Implantol 2016;1: 96-99.

14. Verma PK, Srivastapa R, Gautam A, et al. Multiple regenerative techniques for class II furcation defect. Eur J Gen Dent 2012;1: 90-93.

15. Sharma A, Pradeep AR. Autologous platelet-rich fibrin in the treatment of mandibular degree II furcation defects: a randomized clinical trial. J Periodontol 2011;82: 23-25.

16. Pretzl B, Kim T, Holle R, et al. case series: long-term results of guided tissue regeneration therapy with non-resorbable and bioabsorbable barriers IV a case series of infrabony defects after 10 years. J Periodontol 2008;79: 1491-1499.

17. Reynolds MA, Aichelmann-Reidy ME, Branch-Mays GL. Regeneration of periodontal tissue: bone replacement grafts. Dent Clin N 2010;54: 55-71.

18. Santana RB, de-Mattos LCM, Van-Dyke T. Efficacy of combined regenerative class II furcation defects. J Periodontol 2009;80.

19. Villar Cc, Cochran DL. Regeneration of periodontal tissues: guided tissue regeneration. Dent Clin Na 2010;54: 73-92.

20. Aichelmann-Reidy Me, Avila-Ortiz G, Klokkevold PR. Periodontal regeneration furcation defects: practical applications from the AAP regeneration workshop. Clin Adv Periodontics 2015;5.

21. Tammama T, Syamsudin E, Faturrachman. Alveolar cleft closure with iliac bonegraft: a case report. J Dentomaxillofac Sci 2017;3: 37-40.

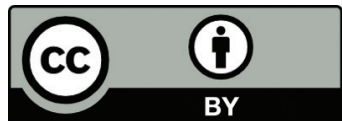

This work is licensed under a Creative Commons Attribution 